\title{
Two Cases of Inadvertent Dental Aerosol Exposure to COVID-19 Patients
}

\section{Dear Editor,}

Aerosol generating procedures (AGP) are routinely performed in dentistry. A large volume of aerosolised saliva can be generated when rotary air-driven dental handpieces, ultrasonic scalers, air polishers, air abrasion units and water jets are used in the operatory. ${ }^{1}$ A recent study has postulated that the risk of transmission through aerosolised saliva is possible as the presence of SARS-CoV-2 was detected in the saliva of COVID-19 patients. $^{2}$ Therefore, the nosocomial transmission of COVID-19 is possible in dentistry and dental practitioners are considered to have a very high exposure risk according to Occupational Safety and Health Administration. ${ }^{3}$

Although contact and respiratory droplets such as aerosols $(>5 \mu \mathrm{m})$ are the established modes of COVID-19 transmission, transmission via airborne droplets nuclei $(<5 \mu \mathrm{m})$ cannot be completely ruled out. ${ }^{4,5}$ Therefore, apart from contact and droplet precautions, the World Health Organisation (WHO) recommends additional precautions for aerosol generating procedures. ${ }^{4}$ This entails the use of a fit-tested particulate respirator (N95 or equivalent, or higher level of protection) as part of an increased level of personal protective equipment (PPE).

As community transmission of COVID-19 continues, inadvertent aerosol exposure from infected patients can occur when providing routine dental care. To date, there is limited literature on the risk of nosocomial transmission in dentistry as COVID-19 is an emerging disease. There is also no consensus on whether dental practitioners are adequately protected when providing dental care using Standard Precautions. Herein, we report 2 cases of inadvertent aerosol exposure to COVID-19 patients in a dental setting without the use of a fit-tested particulate respirator and the clinical outcome of the dental teams following the exposure.

\section{Case Presentation}

\section{Case 1}

A male patient with no recent travel history to high-risk areas before the onset of COVID-19 symptoms had presented to a dental clinic on 2 occasions for dental treatment. During his dental visits, oral examination and scaling were carried out. On the day of his second dental visit, he presented to a hospital and was tested positive for COVID-19 infection. The dentist, a dental hygienist and a dental assistant who had come into close contact with the patient during the dental visits were quarantined for 14 days. This was because the dental team was inadvertently exposed to aerosol generating dental procedures without wearing fit-tested particulate respirator while treating a symptomatic patient who subsequently tested positive for COVID-19. They were wearing PPE, which included surgical masks and eye protection. None of the dental team members was infected after the exposure and quarantine period.

\section{Case 2}

A female patient with no recent travel history to high-risk areas before the onset of COVID-19 symptoms had presented to a dental clinic for dental treatment. Root canal treatment was performed during her dental visit. She had onset of sore throat and cough in the evening before the dental visit. She subsequently presented to a hospital and tested positive for COVID-19 infection. The dentist and three dental assistants who had come into close contact with the patient were quarantined for 14 days. This was because the dental team was inadvertently exposed to aerosol generating dental procedures without wearing fit-tested particulate respirator while treating a symptomatic patient who subsequently tested positive for COVID-19. They were wearing PPE, which included surgical masks and eye protection. None of the dental team members was infected after the exposure and quarantine period.

\section{Discussion}

In the 2 cases reported here, none of the dental team members contracted COVID-19 even though fittested particulate respirators were not used for aerosol generating dental procedures. This suggests that Standard Precautions currently practised by dental 
practitioners may have provided substantial protection against COVID-19 transmission in dental settings. ${ }^{6}$ The routine use of procedural controls may have also helped to reduce the risk of transmission, but their exact significance cannot be evaluated. In a similar case report from Singapore, 41 medical staff managing a patient who was later found to be COVID-19 positive did not develop any infection of COVID-19. This was despite aerosol generating procedures being carried out on the patient, and only $15 \%$ of the medical staff were wearing N95 respirators. The other $85 \%$ were wearing surgical masks while treating the patient. The authors suggested that by wearing a surgical mask and observing precautions like hand hygiene, the risk of infection might not be significantly higher compared to wearing an N95 respirator when treating COVID-19 patients. $^{7}$

Current Standard Precautions measures in dentistry have been reported to be sufficient in preventing transmission of many infectious diseases, including influenza and rhinovirus. ${ }^{8}$ This was similarly observed in the SARS outbreak, where there were no reports of nosocomial transmission during dental care. ${ }^{6}$

As COVID-19 is a new disease, there is a lack of data on whether dental practitioners are adequately protected when providing aerosol generating procedures while wearing surgical marks. Surgical masks are considered to be ineffective against transmission of airborne droplet nuclei pathogens. ${ }^{8}$ It has been demonstrated in in-vitro studies that surgical masks on average provide a 6-fold reduction in exposure to live aerosolised virus $(<1.2 \mu \mathrm{m})$, whereas a properly fitted respirator can provide at least a 100 -fold reduction. ${ }^{9} 10$ Despite such findings, most clinical studies are unable to find a clear benefit of fit-tested respirators over surgical masks against pathogens such as influenza and SARS. ${ }^{11,12}$ There are no similar studies available for SARS-CoV-2, and it remains a controversial topic. It is important to note that surgical masks and respirator use, although critical, are only part of a series of infection control measures.

During this COVID-19 pandemic, additional precautionary measures should be implemented in healthcare facilities, including dental practices, as a systemic approach to mitigate the risk of nosocomial transmission. These measures can be divided into preprocedural, procedural and postprocedural measures. ${ }^{13}$ Firstly, preprocedural measures which should be implemented include triaging of all patients, monitoring the health of staff, safe distancing and team segregation. Procedural measures include observing standard precautions, practising proper hand hygiene and donning PPE appropriate for the procedure. Lastly, postprocedural measures include proper equipment and surface decontamination, regular cleaning of common areas and proper handling of waste.

Triaging of patients for signs and symptoms of COVID-19 plays a significant role in determining if the patients are suspect cases. ${ }^{14}$ However, this process is not entirely infallible because part of the process depends on self-reporting of symptoms via questionnaires. Furthermore, recent studies have also suggested that presymptomatic and asymptomatic COVID-19 patients can be infectious. ${ }^{15,16}$

Most of the current guidelines have advised for an increased level of infection control measures when treating COVID-19 patients to prevent nosocomial infection in dentistry. It is prudent for dental practitioners to follow such guidelines. ${ }^{14,17,18}$ Despite the lack of complete information on an emerging disease, experts are able to draw references from previous respiratory infection pandemics to recommend a good risk management strategy which errs on the side of caution for infection control measures. ${ }^{19}$

\section{Conclusion}

In summary, this article reported 2 cases of inadvertent aerosol exposure to COVID-19 patients in dental settings whereby nosocomial infection did not happen. It is important to note that surgical masks and respirator use, although critical, are only part of a series of infection control measures. We postulate that the summation of infection control measures practised by the dental practitioners may have provided substantial protection against COVID-19 transmission.

\section{REFERENCES}

1. Harrel SK, Molinari J. Aerosols and splatter in dentistry: A brief review of the literature and infection control implications. J Am Dent Assoc 2004;135:429-37.

2. To KK, Tsang OT, Chik-Yan Yip C, Chan KH, Wu TC, Chan JMC et al. Consistent detection of 2019 novel coronavirus in saliva. Clin Infect Dis. 2020; Epud ahead of print.

3. U.S. Department of Labor Occupational Safety and Health Administration. Guidance on Preparing Workplaces for COVID-19, May 2020. Available from: https:/www.osha.gov/Publications/ OSHA3990.pdf. Accessed on 5 July 2020. 
4. World Health Organization. Infection prevention and control during health care when novel coronavirus ( $\mathrm{nCoV})$ infection is suspected, 19 March 2020. Available from: https://www.who.int/ publications-detail/infection-prevention-and-control-during-healthcare-when-novel-coronavirus-(ncov)-infection-is-suspected-20200125. Accessed on 5 July 2020.

5. World Health Organization. Modes of transmission of virus causing COVID-19: implications for IPC precaution recommendations, 29 March 2020. Available from: https://www.who.int/news-room/ commentaries/detail/modes-of-transmission-of-virus-causing-covid19-implications-for-ipc-precaution-recommendations. Accessed on 5 July 2020.

6. Samaranayake LP, Peiris M. Severe acute respiratory syndrome and dentistry. A retrospective review. J Am Dent Assoc 2004;135:1292-302.

7. Ng K, Poon BH, Puar THK, Quah JLS, Loh WJ, Wong YJ, et al. COVID-19 and the risk to health care workers: A case report. Ann Intern Med 2020;172:766-767.

8. Harte JA. Standard and Transmission-Based Precautions. An update for dentistry. J Am Dent Assoc 2010;141:572-81.

9. Gawn JM, Clayton M, Booth CM, Crook B. Evaluating the protection afforded by surgical masks against influenza bioaerosols. J Hosp Infect 2013;84:22-26.

10. Booth CM, Clayton M, Crook B, Gawn JM. Effectiveness of surgical masks against influenza bioaerosols. J Hosp Infect 2013;84:22-6.

11. Offeddu V, Yung CF, Low MSF, Tam CC. Effectiveness of masks and respirators against respiratory infections in healthcare workers: A systematic review and meta-analysis. Clin Infect Dis 2017; $65: 1934-42$

12. Radonovich Jr LJ, Simberkoff MS, Bessesen MT, Brown AC, Cummings DAT, Gaydos CA, et al. N95 respirators vs medical masks for preventing influenza among health care personnel: A randomized clinical trial. JAMA 2019;322:824-33.

13. Shi AH, Guo W, Chng CK, Chan BH. Precautions When Providing Dental Care During Coronavirus Disease 2019. Ann Acad Med Singapore. 2020;49:312-9.

14. Centers for Disease Control and Prevention (CDC). Interim Infection Prevention and Control Recommendations for Healthcare Personnel During the Coronavirus Disease 2019 (COVID-19) Pandemic, 22 May 2020. Available from: https://www.cdc.gov/ coronavirus/2019-ncov/hcp/infection-control-recommendations.html. Accessed on 5 July 2020.

15. Tong ZD, Tang A, Li KF, Li P, Wang HL, Yi JP, et al. Potential Presymptomatic Transmission of SARS-CoV-2, Zhejiang Province, China, 2020. Emerg Infect Dis 2020;26:1052-4.

16. Wei WE, Li Z, Chiew CJ, Yong SE, Toh MP, Lee VJ. Presymptomatic Transmission of SARS-CoV-2 - Singapore, January 23-March 16, 2020. MMWR Morb Mortal Wkly Rep 2020;69:411-5.

17. European Centre for Disease Prevention and Control. ECDC Technical Report: Personal protective equipment (PPE) needs in healthcare settings for the care of patients with suspected or confirmed novel coronavirus (2019-nCoV), February 2020. Available from: https:/www.ecdc.europa.eu/sites/default/files/documents/novelcoronavirus-personal-protective-equipment-needs-healthcare-settings. pdf. Accessed on 5 July 2020.

18. World Health Organization. Advice on the use of masks in the context of COVID-19, 5 June 2020. Available from: https://www.who.int/ publications-detail/advice-on-the-use-of-masks-in-the-communityduring-home-care-and-in-healthcare-settings-in-the-context-of-thenovel-coronavirus-(2019-ncov)-outbreak. Accessed on 5 July 2020.

19. Tay J, Ng YF, Cutter JL, James L. Influenza A (H1N1-2009) pandemic in Singapore - public health control measures implemented and lessons learnt. Ann Acad Med Singapore 2010;39:312-3.

Weidi Guo, ${ }_{B D S, M D S}$, Boon Hui Chan, ${ }^{2}{ }_{B D S, M D S}$, Chai Kiat $\underline{\text { Chng, }}{ }^{3} B D S, M D S, F A M S$, Adrian HY Shi, ${ }^{4} B D S, M D S$

1 Dental Branch, MMI, Singapore Armed Forces Headquarters Medical Corps, Singapore

2 Dental Service, KK Women's and Children's Hospital, Singapore

3 Office of the Director of Medical Services, Ministry of Health, Singapore 4 Department of Oral and Maxillofacial Surgery, National Dental Centre, Singapore

Address for Correspondence: Dr Adrian HY Shi, Department of Oral and Maxillofacial Surgery, National Dental Centre Singapore, 5 Second Hospital Avenue, Singapore 168938

Email: adrian.shi.h.y@ndcs.com.sg 